\title{
Factors affecting puberty gingivitis in Polish girls with adolescent idiopathic scoliosis
}

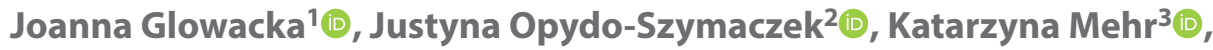 \\ Grazyna Jarzabek-Bielecka4 ${ }^{4}$, Jakub Glowacki ${ }^{5}$ (]) \\ ${ }^{1}$ Postgraduate Studies in Scientific Research Methodology, Poznan University of Medical Sciences, Poznan, Poland \\ ${ }^{2}$ Department of Pediatric Dentistry, Poznan University of Medical Sciences, Poznan, Poland \\ ${ }^{3}$ Department of Gerodontology and Oral Pathology, Poznań University of Medical Sciences, Poznan, Poland \\ ${ }^{4}$ Division of Developmental Gynecology and Sexology, Department of Perinatology and Gynecology, \\ Poznan University of Medical Sciences, Poznan, Poland \\ ${ }^{5}$ Department of General Orthopedics, Musculoskeletal Oncology and Trauma Surgery, \\ Poznan University of Medical Sciences, Poznan, Poland
}

\begin{abstract}
Objectives: Age at menarche and hormonal disturbances have been linked to the occurrence and severity of adolescent idiopathic scoliosis (AIS). Concomitantly, an increase in the production of sex hormones during puberty may result in steroid hormones-related gingivitis. Thus, the study aimed to assess the prevalence and factors affecting puberty gingivitis, including menarcheal status, in female patients with AIS and control subjects.

Material and methods: The study group was comprised of 59 girls aged 12-16 years with AIS and 50 healthy controls. Dental examination included the assessment of oral hygiene, gingivitis, and dental caries intensity. Data were statistically analyzed with a significance taken as $p<0.05$

Results: There wasn't any statistically significant difference in the age at menarche and menarcheal status of both groups. During regression analysis, three predictors significantly affected gingival status of girls: oral hygiene, orthopedic condition, and laterality of the curve. Scoliosis and left convex of the curve significantly increased the index of gingival inflammation.

Conclusions: The results indicate that gingivitis is frequent among female adolescents with AIS, due to poor oral hygiene and higher susceptibility to inflammation. It emphasizes a need for a development of preventive strategy for scoliotic patients, since incipient periodontal problems in children may turn into irreversible advanced periodontal diseases in adults. Key words: adolescent idiopathic scoliosis; puberty gingivitis; menarche
\end{abstract}

Ginekologia Polska 2020; 91, 3: 103-110

\section{INTRODUCTION}

Idiopathic scoliosis is a three-dimensional structural deformity of the spinal column that occurs in up to $3 \%$ of children globally [1]. Adolescent idiopathic scoliosis (AIS) is the most common form and in $80 \%$ of cases occurs in girls. The etiopathogensis of this disorder appears to be multifactorial with a genetic tendency to the deformity, which is triggered by biomechanical, neuromuscular, genetic, hormonal and environmental factors $[1,2]$.

AIS can be considered a disorder of growth, with a close association between patient's maturity and a risk of spinal curve progression [3]. An informative marker of female physical maturity and remaining growth potential during adolescence is the age of menarche [4]. Research studies revealed that the progression of the spinal deformity was related to growth velocity and thus significantly greater before menarche than after menarche [3]. Age at menarche was also linked to the occurrence of scoliosis. Delayed puberty and late age at menarche were associated with a higher prevalence of AIS and an increased risk of curve progression $[3,5]$, although the opposite tendency towards an early onset of menarche in scoliotic patients was also reported $[6,7]$. The observed differences of menarcheal age of AIS patients as compared to healthy population have been 
attributed to hormonal disturbances involving estrogen, melatonin, and leptin $[5,8]$. Several studies have linked high body mass index (BMI) with earlier puberty $[4,9]$. Interestingly, low BMI has also been found to be associated with AIS $[10,16]$, although literature data regarding nutritional status of scoliotic patients are inconclusive [11, 12].

Sex hormones play an important role in the growth, maturation, and maintenance of bone [13-15]. Warren et al. [16] suggested that delayed menarche and prolonged intervals of amenorrhea that reflect prolonged hypoestrogenism may predispose young ballet dancers to scoliosis and stress fractures. In Esposito's study, the blood content of testosterone, $17 \beta$-estradiol, and progesterone in adolescent females with AIS was lower than in their healthy age-mates [17], while Raczkowski observed increased testosterone and normal estrogen levels in girls with AIS [18]. Additionally, estrogen receptors polymorphisms have been suggested to be possible molecular markers for AIS prognosis [17, 19].

As far as oral tissues are concerned, sex hormones have been shown to exert influence on differentiation, proliferation, and growth of fibroblasts, and keratinocytes of periodontium. Estrogens reduce keratinization and effectiveness of epithelial barrier, stimulating proliferation of gingival fibroblasts and synthesis of periodontal connective tissue. Progesterone enhances blood circulation in capillary vessels, increases vascular permeability. and stimulate the production of prostaglandins. An increase in the production of sex hormones during puberty results in steroid hormones-related gingivitis characterized by gingival enlargement, increased inflammation, gingival bleeding, and microbial changes. The highest prevalence of puberty gingivitis falls at the age of 12 years, 10 months in girls and 13 years, 7 months in boys, which is coherent with the onset of puberty $[20,21]$.

Although it is widely accepted that patients with AIS should be screened for orthodontic problems [22], there are scarce data on their general oral health condition [23].

Thus, the aim of the study was to assess the prevalence and factors affecting puberty gingivitis, including menarcheal status, in female patients with AIS and control subjects.

\section{MATERIAL AND METHODS}

The research project was approved by the Bioethics Committee of the Poznan University of Medical Sciences (resolution no. 1307/18) and written informed consent was obtained from the parents and 16-year-old patients.

The study group was comprised of 59 female patients aged 12-16 years, who visited the pediatric orthopedic outpatient office (Poznan, Wielkopolska Province) for the conservative treatment of AIS with a Cheneau brace and had no previous orthodontic or periodontal treatment. Anterior/posterior spine $\mathrm{x}$-rays were used to assess curve direction, and the severity of scoliosis expressed by the Cobb angle, according to the methodology by Harms Study Group [24]. The inclusion criteria were as follows: female gender, age 12-16 years old, a Cobb angle of 20-40, absence of any diagnosed systemic disease (including obesity and moderate to severe acne according to Investigator's Global Assessmentscale) or any medications of continuous use. Only patients with fully erupted permanent dentition (excluding wisdom teeth) were included in the study. Twenty-four patients had thoracic scoliosis, 22 patients had thoracolumbar scoliosis, and the remaining 13 patients had lumbar scoliosis. In 30 patients, scoliosis was convex to the right and in 29 patients to the left.

The control group of 50 orthopedically healthy females aged 12-16 with no history of systemic disease (including obesity and moderate to severe acne) and medications of continuous use, without previous orthodontic or periodontal treatment was recruited in two randomly selected schools in Wielkopolska Province, Poland. Their selection was carried out by an orthopedic surgeon and a dentist based on Adam's forward bend test, the measurement of trunk rotation with the use of Bunnel scoliometer and the dental examination. Cases with a trunk rotation exceeding $4^{\circ}$ were excluded from the study [25].

The patients from the study group were seen in the outpatient orthopedic clinic, while patients from the control group were seen at the school nurse's office. They were examined under the following conditions: the girl seated in a chair, an examiner stood in front of the chair with dental loupes with led light, a mouth mirror, and a WHO probe [26].

The dental caries was evaluated with the use of the number of teeth affected by caries (DT), teeth missing due to caries (MT) and restored due to caries (FT) calculated for all permanent teeth (DMFT). Dental caries diagnosis was based on visual and tactile examination in artificial light, with the use of a mouth mirror and a blunt probe. Active caries was recorded when the lesion showed a visible cavity, undermined enamel, or a softened area. Tooth restored due to caries (FT) was recorded when a tooth had at least one final restoration placed to treat caries. The missing (MT) component of DMFT was recorded when a tooth had been removed due to caries complications.

The gingival condition was assessed with the use of the Gingival Index (Gl) by Löe and Silness on the six index teeth: upper right first molar, lower left first molar, upper right lateral incisor, lower left lateral incisor, upper left first premolar, and lower right first premolar). Marginal and interproximal tissues were scored separately. The criteria were: $0=$ healthy gingiva; $1=$ mild inflammation (slight change in color and edema without bleeding upon probing); $2=$ moderate inflammation (edema, redness, and glazing, bleeding upon probing); 3 = severe inflammation (marked edema 
and redness, ulceration with a tendency to spontaneous bleeding). The values of the four areas around the index tooth were summed and divided by four to calculate the $\mathrm{Gl}$ for the tooth. The $\mathrm{Gl}$ of the patient was obtained by adding the scores of each index tooth and dividing by the number of the teeth examined. The mean Gl was used to assign categorical gingival status to the individual as follows: 0 , healthy gingiva; $0.1-1.0$, mild gingivitis; $1.1-2.0$, moderate gingivitis; 2.1-3.0, severe gingivitis [27].

The evaluation of the oral hygiene by Silness-Löe plaque index (PLI) was carried out by recording plaque deposits on the same six index teeth. Each of the four surfaces of the teeth (lingual, buccal, distal, and mesial) was given a score from 0 to 3 . The values from the four areas of the tooth were added and divided by four in order to calculate the PLI for the tooth with the following criteria: $0=$ no plaque; $1=$ a film of plaque adhering to the gingival margin and adjacent area of the tooth surface which can be detected by the probe; 2 = moderate accumulation of soft debris within the gingival pocket, or the tooth and gingival margin which can be seen with the naked eye; $3=$ abundance of soft matter within the gingival pocket and/or on the tooth and gingival margin. The PLI of the patient was obtained by adding the scores of each index tooth and dividing by the number of the teeth examined. The subject's plaque status was assigned as follows: poor (2.0-3.0); fair (1.0-1.9); good (0.1-0.9); and excellent $(<0.1)$ [27].

Age at menarche was defined as age at the first menstrual bleeding, given in full years. Height and weight measures for the study group and for the control group were collected from the orthopedic patient's files and from school nurses' records, respectively. Diagnosis of overweight and obesity was based on body mass index (BMI). As proposed by World Health Organization, for children aged 5-19 years obesity and overweight correspond to BMI-for-age greater than 2 standard deviations and 1 standard deviation above the growth reference median, respectively [28].

\section{Statistical analysis}

The data was analyzed statistically by Statistica (version 12) for Windows 10 Home (version 10.0.15063) with significance taken as $\mathrm{p}<0.05$.

Three general linear regression analysis models were built with $\mathrm{Gl}$ as the dependent variable. As a first step, a correlation analysis between $\mathrm{Gl}$ and all the independent variables was performed using Spearman's rank correlation coefficient. Additionally, qualitative predictors were assessed with the use of Mann-Whitney's U Test and Gl as the grouping variable. The aim of this step was to select the candidate independent variables for the regression analysis. Regression models included all covariates associated with $\mathrm{GI}$ with a p value $<0.20$. PLI, patient's status (scoliosis vs control) and the presence of menarche were independent variables for the first two models explaining $\mathrm{Gl}$ in all subjects. PLI, the presence of menarche, and laterality of the curve were independent variables for the last model explaining $\mathrm{Gl}$ in the study group. Backward elimination procedure allowed for the construction of an optimal regression equation.

First model was based on data concerning all subjects. Since oral hygiene indices of scoliotic patients and controls differed significantly, the second model of regression was prepared after the selection of subjects with good/excellent oral hygiene ( $\mathrm{PLI}<1.0)$. The third model explained Gl of scoliotic girls with good/excellent oral hygiene. The standardized regression coefficients $(\beta)$, coefficients of determination $\left(R^{2}\right)$, and statistical significance ( $p$ value) were reported.

\section{RESULTS}

Table 1 shows characteristics of the study subjects. Among the 109 patients analyzed, there were 7 scoliotic and 13 non-scoliotic premenarcheal girls, 2 scoliotic and 1 non-scoliotic girl reported late menarche ( $>14$ years of age). The difference between the number of patients with menarche in both groups was not statistically significant ( $p=0.0575$ ). The mean age at menarche in postmenarcheal girls in the study and the control group was similar (12.4 and 12.3 years, respectively). The number of patients with overweight was statistically significantly lower in the study group as compared to the control group (7 and 16, respectively, $p=0.0103$ ), although mean $B M I$ scores in both groups were similar (20.1 and 20.7, respectively).

There was a significant difference between PLI indices of scoliotic and non-scoliotic patients ( 1.01 vs $0.51, p=0.0008$, respectively). The number of patients with excellent/good oral hygiene was significantly lower in the study group, as compared to the control group (33 and 40, respectively, $\mathrm{p}=0.0078$ ). Poor oral hygiene ( $\mathrm{PLI} \geq 2$ ) was significantly more common among AIS patients $(p=0.0304)$. Healthy gingiva $(\mathrm{Gl}=0)$ was significantly more common in the control group $(p<0.0001)$, while mild gingivitis $(G I=0.1-1.0)$ and moderate to severe gingivitis $(\mathrm{Gl}=1.1-2.0)$ were observed more frequently in the study group $(p=0.0037$ and $p=0.0184$, respectively). Scoliotic girls with good/excellent oral hygiene had significantly higher $\mathrm{Gl}$ as compared to controls ( $p=0.0083$ ).

Table 2 presents correlation coefficients between GI and other quantitative variables. There was a strong correlation between $\mathrm{GI}$ and PLI scores with Spearman's rank correlation coefficient of 0.57 and 0.84 for the control group and the study group, respectively, and $p<0.0001$ for both. No significant correlation was found between $\mathrm{Gl}$ and any other variable, such as BMI score, DMF index and age in both groups, as well as Cobb in the study group ( $p>0.05$ ). 
Table 1. Characteristics of the study subjects and statistical differences between the study and the control group

\begin{tabular}{|c|c|c|c|c|}
\hline Variable & & $\begin{array}{l}\text { Control group } \\
n=50\end{array}$ & $\begin{array}{l}\text { Study group } \\
n=59\end{array}$ & $\begin{array}{l}\text { p } \\
\text { (Mann-Whitney's U test, chi-square test) }\end{array}$ \\
\hline \multirow{3}{*}{ Age [years] } & Mean \pm SD & $14.2 \pm 1.7$ & $14.0 \pm 1.3$ & \multirow{3}{*}{0.4829} \\
\hline & Median & 14.0 & 14.0 & \\
\hline & Range & $12.0-16.0$ & $12.0-16.0$ & \\
\hline \multirow{3}{*}{ Cobb angle $\left[{ }^{\circ}\right]$} & Mean \pm SD & N.A. & $27.76 \pm 6.30$ & N.A. \\
\hline & Median & N.A. & 26.00 & N.A. \\
\hline & Range & N.A. & $20.00-40.00$ & N.A. \\
\hline \multirow{3}{*}{$\begin{array}{l}\text { Age at menarche [years] } \\
\mathrm{n}=89\end{array}$} & Mean \pm SD & $12.3 \pm 0.9$ & $12.4 \pm 1.0$ & \multirow{3}{*}{0.5160} \\
\hline & Median & 12.00 & 12.00 & \\
\hline & Range & $11.00-16.00$ & $10.00-15.00$ & \\
\hline Absence of menstruation & $\mathrm{n}(\%)$ & $13(26 \%)$ & $7(12 \%)$ & 0.0575 \\
\hline Late menarche ( $>14$ years) & $\mathrm{n}(\%)$ & $1(2 \%)$ & $2(3 \%)$ & 0.6585 \\
\hline \multirow[t]{3}{*}{ BMI } & Mean \pm SD & $21.0 \pm 2.4$ & $20.7 \pm 1.9$ & \multirow{3}{*}{0.4417} \\
\hline & Median & 20.7 & 20.1 & \\
\hline & Range & $16.0-26.3$ & $18.5-20.6$ & \\
\hline Overweight & $\mathrm{n}(\%)$ & $16(32 \%)$ & $7(13 \%)$ & $0.0103^{*}$ \\
\hline \multirow{3}{*}{ PLI } & Mean \pm SD & $0.51 \pm 0.65$ & $1.01 \pm 0.91$ & \multirow{3}{*}{$0.0008^{*}$} \\
\hline & Median & 0.30 & 0.80 & \\
\hline & Range & $0.00-2.50$ & $0.00-3.00$ & \\
\hline PLI < 1.0 (excellent/good hygiene) & $\mathrm{n}(\%)$ & $40(80 \%)$ & $33(56 \%)$ & $0.0078^{*}$ \\
\hline $\mathrm{PLI}=1.0-1.9$ (fair hygiene) & $\mathrm{n}(\%)$ & $7(14 \%)$ & $14(24 \%)$ & 0.1994 \\
\hline $\mathrm{PLI}=2.0-3.0$ (poor hygiene) & $\mathrm{n}(\%)$ & $3(6 \%)$ & $12(20 \%)$ & $0.0304^{*}$ \\
\hline $\mathrm{Gl}=0$ (healthy gingiva) & $\mathrm{n}(\%)$ & $38(76 \%)$ & $20(34 \%)$ & $0.0000^{*}$ \\
\hline $\mathrm{Gl}=0.1-1.0$ (mild gingivitis) & $\mathrm{n}(\%)$ & $9(18 \%)$ & $26(44 \%)$ & $0.0037^{*}$ \\
\hline $\mathrm{Gl}>1.0$ (moderate/severe gingivitis) & $\mathrm{n}(\%)$ & $3(6 \%)$ & $13(22 \%)$ & $0.0184^{*}$ \\
\hline \multirow{3}{*}{$\begin{array}{l}\text { Gl of subjects with good/excellent oral hygiene } \\
n=73\end{array}$} & Mean \pm SD & $0.04 \pm 0.12$ & $0.22 \pm 0.40$ & \multirow{3}{*}{$0.0083^{*}$} \\
\hline & Median & 0.00 & 0.00 & \\
\hline & Range & $0.00-0.50$ & $0.00-2.00$ & \\
\hline \multirow{3}{*}{ DMF } & Mean \pm SD & $3.32 \pm 3.69$ & $3.13 \pm 3.49$ & \multirow{3}{*}{0.7971} \\
\hline & Median & 2.00 & 2.00 & \\
\hline & Range & $0.00-15.00$ & $0.00-16.00$ & \\
\hline Crowding of teeth & $\mathrm{n}(\%)$ & $22(44 \%)$ & 37 (63\%) & 0.0508 \\
\hline
\end{tabular}

$\mathrm{BMI}$ - body mass index; DMF — the total number of teeth that are decayed, missing, or filled; $\mathrm{GI}$ - gingival index; PLI — Silness-Löe plaque index *statistically significant difference $(p<0.05)$

Table 2. Spearman's rank correlation coefficients between $\mathrm{Gl}$ and other quantitative variables

\begin{tabular}{|l|l|l|}
\hline Variables & $\begin{array}{l}\text { Control group } \\
\mathbf{n = 5 0}\end{array}$ & $\begin{array}{l}\text { Study group } \\
\mathbf{n = 5 9}\end{array}$ \\
\hline Age [years] & -0.01 & 0.11 \\
\hline Cobb Angle & N.A. & 0.04 \\
\hline PLI & $0.57^{*}$ & $0.84^{*}$ \\
\hline DMF & 0.25 & 0.03 \\
\hline BMI & 0.12 & -0.01 \\
\hline
\end{tabular}

$\mathrm{BMI}$ - body mass index; DMF — the total number of teeth that are decayed, missing, or filled; PLI - Silness-Löe plaque index

${ }^{*} p<0.0001$, statistically significant
DMF numbers in the study group and the control group were similar (3.12 and 3.32, respectively). There wasn't any statistically significant difference between the prevalence of teeth crowding in the control group and the study group ( $37 \%$ and $44 \%$, respectively) ( $p=0.0505$ ).

Table 3 shows descriptive statistics and Mann-Whitney's $U$ test results for differences between $\mathrm{Gl}$ of selected subgroups of subjects. There was a significant difference between $\mathrm{Gl}$ indices of scoliotic and non-scoliotic patients ( 0.69 vs $0.18, p<0.0001$, respectively).

Postmenarcheal patients did not differ significantly from premenarcheal subjects in terms of $\mathrm{Gl}(0.51$ vs 0.23 ) 


\begin{tabular}{|c|c|c|c|}
\hline Grouping variable & & GI & p (Mann-Whitney's U test) \\
\hline Menarche & $\mathrm{n}$ & Mean \pm SD & \\
\hline Yes & 89 & $0.51 \pm 0.76$ & \multirow{2}{*}{$p=0.1595$} \\
\hline No & 20 & $0.23 \pm 0.40$ & \\
\hline Scoliosis & $\mathrm{n}$ & Mean \pm SD & \\
\hline Yes & 59 & $0.69 \pm 0.82$ & \multirow{2}{*}{$p<0.0001^{*}$} \\
\hline No & 50 & $0.18 \pm 0.44$ & \\
\hline Curve direction & $\mathrm{n}$ & Mean \pm SD & \\
\hline Right & 30 & $0.62 \pm 0.85$ & \multirow{2}{*}{$p=0.1705$} \\
\hline Left & 29 & $0.77 \pm 0.80$ & \\
\hline Crowding & $\mathrm{n}$ & Mean \pm SD & \\
\hline Yes & 59 & $0.48 \pm 0.71$ & \multirow{2}{*}{$p=0.5524$} \\
\hline No & 50 & $0.43 \pm 0.74$ & \\
\hline Overweight & $n$ & Mean \pm SD & \\
\hline Yes & 23 & $0.44 \pm 0.68$ & $p=0.7933$ \\
\hline No & 86 & $0.46 \pm 0.73$ & \\
\hline
\end{tabular}

$\mathrm{Gl}$ — gingival index; ${ }^{*} \mathrm{p}<0.05$, statistically significant

Table 4. Parameters of general regression models obtained after backaward elimination of insignificant variables, predicting the value of $\mathrm{GI}$ based on PLI and orthopedic status (Model 1 and 2), PLI and curve direction (Model 3)

\begin{tabular}{|l|l|l|l|}
\hline & Model 1 & Model 2 & Model 3 \\
\hline$R$ & 0.8545 & 0.4581 & 0.6138 \\
\hline$R^{2}$ & 0.7302 & 0.2099 & 0.3768 \\
\hline Adjusted $R^{2}$ & 0.7251 & 0.1873 & 0.3352 \\
\hline $\mathrm{F}$ & 143.4736 & 9.2962 & 9.0681 \\
\hline $\mathrm{P}$ & $<0.0001$ & 0.0003 & 0.0008 \\
\hline
\end{tabular}

GI — gingival index; PLI — Silness-Löe plaque index

$(p=0.1595)$. Patients with crowding and these without crowding showed similar Gl indices ( 0.48 vs 0.43 , respectively). Patients with left convex did not differ significantly from patients with right convex regarding $\mathrm{Gl}$ ( 0.77 and 0.62 , $p=0.1705)$.

Our regression models allowed us to evaluate the joint effect of selected independent variables on the gingival status of our patients. First model was statistically significant $(p<0.0001)$ with adjusted coefficient of determination $R^{2}=0.7251$. The second and the third one also being statistically significant $(p=0.0003$ and $p=0.0008)$ with adjusted coefficients of determination $R^{2}=0.1873$ and $R^{2}=0.3352$, respectively (Tab. 4). Bearing in mind that $R^{2}$ measures the percentage of the variation in the dependent variable that is explained by variation of the independent variables, we could see that first model explains $73 \%$ variation in the
Table 5. The regression coefficients $(\beta)$ and statistical significance of the independent variables in four models of regression analysis

\begin{tabular}{|c|c|c|}
\hline & \multicolumn{2}{|c|}{$\begin{array}{l}\text { Model } 1, \mathrm{Gl} \text { in all subjects from the study and the } \\
\text { control group }\end{array}$} \\
\hline & $\beta$ & $\mathbf{p}$ \\
\hline PLI & 0.8133 & $<0.0001$ \\
\hline \multirow[t]{2}{*}{ Scoliosis } & 0.1151 & 0.0316 \\
\hline & \multicolumn{2}{|c|}{$\begin{array}{l}\text { Model 2, Gl in subjects with good/excellent oral } \\
\text { hygiene from the study and the control group }\end{array}$} \\
\hline PLI & 0.3619 & 0.0013 \\
\hline \multirow[t]{2}{*}{ Scoliosis } & 0.2194 & 0.0466 \\
\hline & \multicolumn{2}{|c|}{$\begin{array}{l}\text { Model 3, Gl in scoliotic girls with good/excellent } \\
\text { oral hygiene }\end{array}$} \\
\hline PLI & 0.4495 & 0.0041 \\
\hline Left convex & 0.3765 & 0.0143 \\
\hline
\end{tabular}

GI — gingival index; PLI — Silness-Löe plaque index

outcome parameter $(\mathrm{Gl})$, while the second one and the third one (concerning patients with good/excellent oral hygiene) explain $19 \%$ and $33 \%$ of the variation of $\mathrm{Gl}$, respectively.

Table 5 presents the regression coefficients ( $\beta$ ) and statistical significance of the independent variables in three models of regression analysis.

PLI turned out to be the most important predictor of GI $(\beta=0.8133, p<0.0001$ in the first model, $\beta=0.3619$, $p=0.0013$ in the second model, and $\beta=0.4495, p=0.0041$ ). Patient's orthopedic status (scoliosis vs. control) was the second statistically significant predictor of $\mathrm{GI}(\beta=0.1151$, $p=0.0316$ in the first model, $\beta=0.2194, p=0.0466$ in the second model).

Left convex of the curve was a significant predictor of $\mathrm{Gl}$ in the third model prepared for scoliotic patients with good/excellent oral hygiene $(\beta=0.3765, p=0.0143)$.

\section{DISCUSSION}

The prevalence and severity of gingival inflammation in adolescents are influenced by several factors, including oral hygiene, presence of rough and retentive areas on which plaque accumulates such as dental caries lesions, restorations or crowding of the teeth, and physiological teeth eruption [29]. Additionally, the sudden rise in steroid hormone levels during puberty affects the inflammatory status of the gingiva $[29,30]$. Thus, although puberty-associated gingivitis is classified as a plaque-induced gingivitis, the predisposition to gingival inflammation in the presence of relatively small amounts of plaque is a key to distinguishing this condition. The response of gingiva to plaque is increased by circulating sex hormones through mechanisms such as increased fluid secretion, partial immune suppression, and stimulation of fibroblast synthetic activity [21]. Besides, the subgingival microflora (i.e., Prevotella intermedia) can sub- 
stitute progesterone and estrogen for vitamin $\mathrm{K}$, which is an important bacterial growth factor [31]. The relationship between elevated levels of circulating sex hormones and prevalence of gingivitis in puberty is strengthened by the observation that puberty gingivitis peaks earlier in girls than in boys [32]. Gingiva condition of our subjects, who developed inflammation of gums even in the presence of small amounts of plaque (PLI < 1.0), match the criteria of steroid-hormone related gingivitis.

It is noteworthy that an increased BMI might be related to higher estrogen levels due to conversion of androgens to estrogens in adipose tissue. There is a growing scientific evidence supporting a link between increased childhood adiposity and early onset of puberty in girls [9]. At the same time, several studies demonstrate an association between obesity and periodontal problems in adults and adolescents [33-35]. Adipose tissue is not only a source of estrogens, but also pro-inflammatory cytokines (TNF-a, IL-1, IL-6), which play a fundamental role in the progression of periodontitis $[33,35]$. Our results did not confirm the relation between gingival inflammation and BMI. However, most of our subjects had BMI within norm, and obese girls with extreme of BMI were excluded from the analysis.

Although the etiology of the AIS is not fully understood, it is also considered a sex-conditioned disease, in terms of sex hormones levels and their receptors activity. As suggested by Kulis, the multifactorial pathomechanism of AIS involves significant deficiency of estrogens, and especially estradiol [8]. Thus, our assumption was that the study group would present with a higher average age at menarche as compared to the controls and lower risk of steroid-hormone related gingivitis, due to lower levels of circulating sex hormones. Contrary to our expectations, there wasn't any statistically significant difference in the age of menarche and menarcheal status of both groups. Moreover, in the control group of patients the number of girls without menarche was almost twice as high as in the study group. Similarly, Grivas et al. did not observe later menarche in AIS patients, although they found a significant difference between postmenarcheal and premenarcheal scoliotic girls in relation to the laterality of scoliotic curves: the former showed predominantly right sided primary curves while the latter had mainly left sided primary curves [5]. It would suggest that girls with levoscoliosis differ in terms of auxology from the girls with dextroscoliosis. There is also some evidence in the literature, that left-leaning curves are more likely to be accompanied by other health conditions such as neuromuscular disorders, spina bifida, spinal tumors, chromosomal anomalies and rare syndromes [36]. Interestingly, our results suggest that left convex increased a risk of gingival inflammation, although, contrary to Grivas et al. [5] we did not observe any relation between menarcheal status of the girls or the age of menarche and laterality of the scoliotic curve. The question arises whether gingivitis could be a sign of some undiagnosed subclinical health conditions in scoliotic subjects with left convex.

In regression analysis models prepared for all subjects, two predictors significantly affected the gingival status: oral hygiene (PLI) and orthopedic condition (scoliosis vs. control). The first one is nothing unusual since bacterial plaque is considered the main risk factor of puberty gingivitis [31]. As reminded by Laskowska, the patients with AIS and their families tend to focus all their attention and resources on their primary health problem, often neglecting oral health [23]. The second predictor needs further investigation, because, contrary to our initial hypothesis, scoliosis significantly increased the index of gingival inflammation. The effect of orthopedic status on gingiva remained significant after elimination of subjects with poor/fair oral hygiene. To the best of our knowledge, it is the first study which indicates that scoliotic girls may present with an increased risk of puberty gingivitis as compared to their age-mates.

Trying to find the possible explanation of this phenomenon, we must remember that apart from sex hormones levels, expression of steroids receptors, especially estrogen receptor $\alpha(E R a)$ and estrogen receptor $\beta(E R \beta)$ in human periodontal tissues may modify their inflammatory response to dental plaque. Interestingly, polymorphisms in genes encoding estrogen receptors have been associated both with chronic periodontitis and idiopathic scoliosis, although the results of different studies are ambiguous [37, 38]. The effects of estrogen on gingival tissues are mediated by $E R \beta$, which is the most predominant ER in human healthy and inflamed gingivae, while ERa gene polymorphisms are linked to alveolar bone loss in patients with periodontitis $[39,40]$. The rs 1256120 polymorphism in the gene for ER $\beta$ was reported to be associated with AIS predisposition and curve severity in Chinese [19], as well as with an increased risk of chronic periodontitis in Polish adults [41]. Whether estrogens receptors polymorphisms might be responsible for gingival inflammation in female patients suffering from AIS remains to be investigated.

Our study has several limitations that should be considered in the interpretation of the results. We investigated a relatively small number of female patients with low-grade scoliosis, which may limit the generalizability of the findings. Besides, we didn't assess hormonal profiles of the girls which would add valuable information to our analysis. On the other hand, the group was homogenous and inclusion criteria eliminated possible confounding factors related to changes in periodontium: during primary teeth exfoliation and permanent teeth eruption, after invasive orthopedic surgery, after orthodontic and periodontal treatment, due to obesity or potential excess of androgens (manifested as 
moderate to severe acne), as well as due to gender-related hormonal differences.

\section{CONCLUSIONS}

The results indicate that gingivitis is frequent among female adolescents with AIS, due to poor oral hygiene and susceptibility to inflammation increased by additional systemic factor. The nature of this factor is currently unknown and needs further elucidation.

It emphasizes a need for collaboration between orthopedists, pediatric gynecologists, and dentists in the management of AIS, as well as development of preventive strategy for scoliotic patients, since incipient periodontal problems in children may turn into irreversible advanced periodontal diseases in adults.

\section{REFERENCES}

1. Trobisch P, Suess O, Schwab F. Idiopathic scoliosis. Dtsch Arztebl Int. 2010; 107(49): 875-83; quiz 884, doi: 10.3238/arztebl.2010.0875, indexed in Pubmed: 21191550.

2. Fadzan M, Bettany-Saltikov J. Etiological Theories of Adolescent Idiopathic Scoliosis: Past and Present. Open Orthop J. 2017; 11: 1466-1489, doi: 10.2174/1874325001711011466, indexed in Pubmed: 2939922.

3. Mao SH, Jiang J, Sun Xu, et al. Timing of menarche in Chinese girls with and without adolescent idiopathic scoliosis: current results and review of the literature. Eur Spine J. 2011; 20(2): 260-265, doi: 10.1007/s00586010-1649-6, indexed in Pubmed: 21153847.

4. Durda-Masny M, Hanć T, Czapla Z, et al. BMI at menarche and timing of growth spurt and puberty in Polish girls - longitudinal study. Anthropol Anz. 2019; 76(1): 37-47, doi: 10.1127/anthranz/2019/0920, indexed in Pubmed: 30648186.

5. Grivas TB, Vasiliadis E, Mouzakis V, et al. Association between adolescent idiopathic scoliosis prevalence and age at menarche in different geographic latitudes. Scoliosis. 2006; 1: 9, doi: 10.1186/1748-7161-1-9, indexed in Pubmed: 16759371.

6. Goldberg CJ, Dowling FE, Fogarty EE. Adolescent idiopathic scoliosis--early menarche, normal growth. Spine (Phila Pa 1976). 1993; 18(5): 529-535, doi: 10.1097/00007632-199304000-00003, indexed in Pubmed: 8484142.

7. Ylikoski M, Peltonen J, Poussa M. Biological factors and predictability of bracing in adolescent idiopathic scoliosis. J Pediatr Orthop. 1989; 9(6): 680-683, doi: 10.1097/01241398-198911000-00009, indexed in Pubmed: 2600176.

8. Kulis A, Goździalska A, Drąg J, et al. Participation of sex hormones in multifactorial pathogenesis of adolescent idiopathic scoliosis. Int Orthop. 2015;39(6): 1227-1236, doi: 10.1007/s00264-015-2742-6, indexed in Pubmed: 25804208.

9. Kaplowitz PB. Link between body fat and the timing of puberty. Pediatrics. 2008; 121 Suppl 3: S208-S217, doi: 10.1542/peds.2007-1813F, indexed in Pubmed: 18245513.

10. Grivas TB, Burwell RG, Mihas $C$, et al. Relatively lower body mass index is associated with an excess of severe truncal asymmetry in healthy adolescents: Do white adipose tissue, leptin, hypothalamus and sympathetic nervous system influence truncal growth asymmetry? Scoliosis. 2009; 4: 13, doi: 10.1186/1748-7161-4-13, indexed in Pubmed: 19566930.

11. Grivas TB, Arvaniti A, Maziotou C, et al. Comparison of body weight and height between normal and scoliotic children. Stud Health Technol Inform. 2002; 91: 47-53, indexed in Pubmed: 15457692.

12. Matusik E, Durmała J, Matusik $P$, et al. Evaluation of nutritional status of children and adolescents with idiopathic scoliosis: a pilot study. Ortop Traumatol Rehabil. 2012; 14(4): 351-362, doi: 10.5604/15093492.1005093, indexed in Pubmed: 23043058.

13. Holmes SJ, Shalet SM. Role of growth hormone and sex steroids in achieving and maintaining normal bone mass. Horm Res. 1996; 45(1-2): 86-93, doi: 10.1159/000184765, indexed in Pubmed: 8742125.

14. Saggese G, Bertelloni S, Baroncelli GI. Sex steroids and the acquisition of bone mass. Horm Res. 1997; 48 Suppl 5: 65-71, doi: 10.1159/000191331, indexed in Pubmed: 9434047.
15. Hosoi T. Genetic aspects of osteoporosis. J Bone Miner Metab. 2010; 28(6): 601-607, doi: 10.1007/s00774-010-0217-9, indexed in Pubmed: 20697753.

16. Warren MP, Brooks-Gunn J, Hamilton LH, et al. Scoliosis and fractures in young ballet dancers. Relation to delayed menarche and secondary amenorrhea. N Engl J Med. 1986; 314(21): 1348-1353, doi: 10.1056/NEJM198605223142104, indexed in Pubmed: 3451741.

17. Esposito T, Uccello R, Caliendo R, et al. Estrogen receptor polymorphism, estrogen content and idiopathic scoliosis in human: a possible genetic linkage. J Steroid Biochem Mol Biol. 2009; 116(1-2): 56-60, doi: 10.1016/j. jsbmb.2009.04.010, indexed in Pubmed: 19406238.

18. Raczkowski JW. The concentrations of testosterone and estradiol in girls with adolescent idiopathic scoliosis. Neuro Endocrinol Lett. 2007; 28(3): 302-304, indexed in Pubmed: 17627266.

19. Zhang HQ, Lu SJ, Tang MX, et al. Association of estrogen receptor beta gene polymorphisms with susceptibility to adolescent idiopathic scoliosis. Spine (Phila Pa 1976). 2009; 34(8): 760-764, doi: 10.1097/BRS.0b013e31818ad5ac, indexed in Pubmed: 19337134.

20. Sooriyamoorthy $M$, Gower DB. Hormonal influences on gingival tissue: relationship to periodontal disease. J Clin Periodontol. 1989; 16(4): 201-208, doi: 10.1111/j.1600-051x.1989.tb01642.x, indexed in Pubmed: 2654195.

21. Mariotti A, Mawhinney M. Endocrinology of sex steroid hormones and cell dynamics in the periodontium. Periodontol 2000. 2013;61(1):69-88, doi: 10.1111/j.1600-0757.2011.00424.x, indexed in Pubmed: 23240944.

22. Saccucci M, Tettamanti L, Mummolo S, et al. Scoliosis and dental occlusion: a review of the literature. Scoliosis. 2011; 6: 15, doi: 10.1186/17487161-6-15, indexed in Pubmed: 21801357.

23. Laskowska $M$, Tyrakowski $M$, Zadurska $M$, et al. Dental health status and needs associated with conservative and orthodontic treatment in children and adolescents with idiopathic scoliosis. Nowa Stom. 2017; 4: 171-180.

24. D'Andrea LP, Betz RR, Lenke LG, et al. Do radiographic parameters correlate with clinical outcomes in adolescent idiopathic scoliosis? Spine (Phila Pa 1976). 2000; 25(14): 1795-1802, doi: 10.1097/00007632200007150-00010, indexed in Pubmed: 10888948.

25. Bunnell WP. An objective criterion for scoliosis screening. J Bone Joint Surg Am. 1984; 66(9): 1381-1387, indexed in Pubmed: 6501335.

26. Petersen PE, Baez RJ. World Health Organization, Oral health surveys: basic methods, 5th edition. : 2013.

27. Hiremath SS. Textbook of Preventive and Community Dentistry, 2nd Edition. Elsevier. ; 2011.

28. World Health Organization, 2007. Growth reference 5-19. BMI-for-age for girls. https://www.who.int/growthref/bmifa_girls_5_19years_z. pdf?ua $=1$ (December 3, 2019).

29. Caton JG, Armitage G, Berglundh T, et al. A new classification scheme for periodontal and peri-implant diseases and conditions - Introduction and key changes from the 1999 classification. J Clin Periodontol. 2018; 45 Suppl 20:S1-S8, doi: 10.1111/jcpe.12935, indexed in Pubmed: 29926489.

30. Nirola A, Batra P, Kaur J. Ascendancy of sex hormones on periodontium during reproductive life cycle of women. Journal of the International Clinical Dental Research Organization. 2018; 10(1):3, doi: 10.4103/jicdro. jicdro_29_17.

31. Nakagawa $\mathrm{S}$, Fujii $\mathrm{H}$, Machida $\mathrm{Y}$, et al. A longitudinal study from prepuberty to puberty of gingivitis. Correlation between the occurrence of Prevotella intermedia and sex hormones. J Clin Periodontol. 1994; 21(10): 658-665, doi: 10.1111/j.1600-051x.1994.tb00783.x, indexed in Pubmed: 7852609.

32. Markou $E$, Eleana B, Lazaros $T$, et al. The influence of sex steroid hormones on gingiva of women. Open Dent J. 2009; 3: 114-119, doi: 10.2174/1874210600903010114, indexed in Pubmed: 19812718.

33. von Bremen J, Lorenz N, Ruf S. Impact of body mass index on oral health during orthodontic treatment: an explorative pilot study. Eur J Orthod. 2016; 38(4): 386-392, doi: 10.1093/ejo/cjv074, indexed in Pubmed: 26450695

34. Modéer T, Blomberg C, Wondimu B, et al. Association between obesity and periodontal risk indicators in adolescents. Int J Pediatr Obes. 2011; 6(2-2): e264-e270, doi: 10.3109/17477166.2010.495779, indexed in Pubmed: 20707762.

35. Wood N, Johnson RB, Streckfus CF. Comparison of body composition and periodontal disease using nutritional assessment techniques: Third National Health and Nutrition Examination Survey (NHANES III). J Clin Periodontol. 2003; 30(4): 321-327, doi: 10.1034/j.1600-051x.2003.0035 3.x, indexed in Pubmed: 12694430.

36. Goldberg CJ, Moore DP, Fogarty EE, et al. Left thoracic curve patterns and their association with disease. Spine (Phila Pa 1976). 1999; 24(12): 
1228-1233, doi: 10.1097/00007632-199906150-00010, indexed in Pubmed: 10382250.

37. TakahashiY, Matsumoto M, Karasugi T, et al. Replication study of the association between adolescent idiopathic scoliosis and two estrogen receptor genes. J Orthop Res. 2011; 29(6): 834-837, doi: 10.1002/jor.21322, indexed in Pubmed: 21520258.

38. Janusz $P$, Kotwicka $M$, Andrusiewicz $M$, et al. Estrogen receptors genes polymorphisms and age at menarche in idiopathic scoliosis. BMC Musculoskelet Disord. 2014; 15: 383, doi: 10.1186/1471-2474-15-383, indexed in Pubmed: 25410117.
39. Vittek J, Hernandez MR, Wenk EJ, et al. Specific estrogen receptors in human gingiva. J Clin Endocrinol Metab. 1982; 54(3): 608-612, doi: 10.1210/jcem-54-3-608, indexed in Pubmed: 7035487.

40. Zhang Li, Meng $\mathrm{H}$, Zhao $\mathrm{H}$, et al. Estrogen receptor-alpha gene polymorphisms in patients with periodontitis. J Periodontal Res. 2004; 39(5): 362-366, doi: 10.1111/j.1600-0765.2004.00736.x, indexed in Pubmed: 15324358.

41. Wyganowska-Swiatkowska M. Potential Association of Estrogen Receptor 2 Variant with Chronic Periodontitis. Biomedical Journal of Scientific \& Technical Research. 2019; 13(4), doi: 10.26717/bjstr.2019.13.002433. 